\title{
Verständigungsbarrieren zwischen kulturalistischen Sozialwissenschaften und evolutionärer Anthropologie: Ursachen, Argumente und Auswege
}

\author{
Eckart Voland · Christoph Meißelbach
}

Eingegangen: 11. Oktober 2019 / Angenommen: 14. Dezember 2020 / Online publiziert: 15. März 2021 (C) Der/die Autor(en) 2021

Zusammenfassung Kommunikation und Kooperation zwischen sozialwissenschaftlicher und evolutionär-anthropologischer Forschung ist durch einige Verständigungsbarrieren erschwert. In diesem Beitrag werden die wichtigsten dieser Probleme systematisch geordnet und auf die folgenden Fragen hin analysiert: Wo stehen der Annäherung sozialwissenschaftlicher und evolutionär informierter Anthropologie nur Missverständnisse, Falschauffassungen oder ideologisches Misstrauen im Wege; wo sind es unterschiedliche methodologische Herangehensweisen oder paradigmatische Grundüberzeugungen; und wie lassen sich diese Hindernisse interdisziplinärer Theorieintegration überwinden?

Schlüsselwörter Konstruktivismus · Natur/Kultur-Dualismus · Moralistischer und naturalistischer Fehlschluss · Genetischer Determinismus · Ultimate und proximate Ursachen

\footnotetext{
E. Voland $(\triangle)$

Institut für Philosophie der Universität Gießen

Rathenaustraße 8, 35394 Gießen, Deutschland

E-Mail: kontakt@eckart-voland.de

C. Meißelbach

Sächsisches Institut für Polizei- und Sicherheitsforschung, Hochschule der Sächsischen Polizei (FH)

Friedensstr. 120, 02929 Rothenburg/Oberlausitz, Deutschland

E-Mail: christoph@meisselbach.net
} 


\title{
Barriers of Understanding Between Culturalist Social Sciences and Evolutionary Anthropology: Causes, Arguments, and Ways Forward
}

\begin{abstract}
Communication and collaboration between social sciences and evolutionary anthropological research are hampered by several barriers to understanding. In this essay, we systematically identify and classify some of the most important problems and analyze them regarding the following questions: Where do mere misconceptions or ideological distrust stand in the way of a convergence between social sciences and evolutionary anthropology? Where are there different methodological approaches or fundamental paradigmatic convictions? And finally, how can these obstacles to an interdisciplinary theoretical integration be overcome?
\end{abstract}

Keywords Constructivism · Nature-culture dualism · Moralistic and naturalistic fallacy $\cdot$ Genetic determinism - Ultimate and proximate causes

\section{Wer diskutiert: Evolutionisten und Kulturalisten}

Die Wechselwirkungen von menschlichem Sozialverhalten und gesellschaftlichen Strukturen zu verstehen sowie zu erklären, ist das gemeinsame Forschungsziel gleich mehrerer wissenschaftlicher Disziplinen. Deren theoretische und empirische Anfänge liegen wesentlich in der zweiten Hälfte des 19. Jahrhunderts. Seitdem haben sich zwei eigenständige Denktraditionen entfaltet und in komplexen Forschungssträngen ausdifferenziert, die dieses Ziel verfolgen. Beiden ist gemeinsam, dass sie menschliches Verhalten aus ihrer Geschichtlichkeit heraus verstehen wollen. Jedoch unterscheiden sie sich deutlich in ihrem Verständnis solcher Historizität.

Für den einen Forschungsstrang ist menschliches Sozialverhalten in erster Linie ein Resultat sozialer Tatsachen, ihrerseits kontingente Resultate kulturgeschichtlicher Entwicklungen. „Omnis cultura ex cultura“ lautet die Formel, mit der Lowie (1966, S. 25) diese Sichtweise auf den Punkt brachte. Anhänger dieser Denktradition berufen sich auf Vordenker wie Émile Durkheim, Karl Marx, Franz Boas, Pierre Bourdieu oder Michel Foucault. Diese Fraktion (der sprachlichen Einfachheit halber im Folgenden als „Kulturalisten“ bezeichnet) ist in unserer Zeit gut vertreten in den Sozialwissenschaften, insbesondere der Kulturanthropologie, der Soziologie und der Politikwissenschaft.

Demgegenüber sehen Vertreter des anderen Strangs den Menschen fest eingebunden in die Naturgeschichte des Lebens. Sie gründen ihre Forschungsstrategien auf der Überzeugung, dass Menschen - wie alle anderen Organismen auch - konsequent und ausnahmslos mit den Implikationen des biologischen Evolutionsgeschehens behaftet sind. „Nichts ergibt Sinn in der Biologie, außer im Lichte der Evolution“; dieses oft zitierte Diktum von Dobzhansky (1973) soll auch für das Sozialverhalten gelten. Unter Berufung auf Charles Darwin arbeitet diese Fraktion (hier ,Evolutionisten“ bzw. „Evos“ genannt) heute in verschiedenen Disziplinen, die sich unter dem Oberbegriff der Evolutionären Anthropologie zusammenfassen lassen, vor allem in Humanethologie, Soziobiologie, evolutionärer Psychologie und Verhaltensökologie. 
Darwins Ideen wurden von Sozialtheoretikern anfänglich mit großem Interesse rezipiert. Herbert Spencer, der mit seinen (erst später von Darwin übernommenen) Floskeln vom „survival of the fittest“ und „struggle for life“ zu den einflussreichsten Popularisierern der darwinschen Evolutionstheorie gehörte, war Philosoph und Soziologe. Auch Karl Marx entwickelte eine Affinität zu Darwin, denn Kampf ums Dasein sorge für Fortschritt, und Fortschritt sei nicht ohne Kampf zu bekommen. Die sozialistische Arbeiterbewegung schien etwas Naturgesetzliches an sich zu haben und galt gerade deshalb als bestens legitimiert. Und auch Durkheim war nicht frei von einer evolutionären Perspektive, wenngleich - wie auch Marx - im heute als falsch erkannten Sinne eines zielorientierten Prozesses (Mesoudi et al. 2010; Runciman 2008).

Diese vermeintliche Einvernehmlichkeit währte jedoch nur kurz und machte einer Konkurrenzbeziehung Platz, die sich besonders in der zweiten Hälfte des 20. Jahrhunderts aufschaukelte und dermaßen an emotionaler Involviertheit der Beteiligten gewann, dass die Beobachter dieser Zeit von regelrechten ,sociobiology wars“ sprachen (Segerstråle 2000). Die Gründe für diese Eskalation haben einerseits viel mit einer mutmaßlichen Nähe evolutionären Denkens zu politischem Sozialdarwinismus, Eugenik und Rassismus zu tun, andererseits mit der Agenda einer sich politisch links verstehenden Gruppe von Wissenschaftlern, für die politische und wissenschaftliche Kritik legitimerweise ineinander verschmolzen. Diese Gründe sind an anderer Stelle ausführlich dargelegt worden (Laland und Brown 2002; Perry und Mace 2010; Segerstråle 2000; Weingart et al. 1997) und sollen hier nicht weiter erörtert werden.

Stattdessen soll es in diesem Aufsatz um einen Beitrag zu der Frage gehen, was etwa eine Forschergeneration nach den ,sociobiology wars“ aus dieser Entzweiung geworden ist. Wie stellt sie sich heute dar? Welchen Status hat sie: einen eher weltanschaulichen, politischen oder wissenschaftstheoretischen? Was an ihr erschwert gelegentlich immer noch einen konstruktiven Austausch zwischen Sozialwissenschaften und Evolutionärer Anthropologie? Warum lassen sich diese Kommunikationsbarrieren so schwer überwinden und wie kann es vielleicht doch gelingen?

Wenn im Zuge der Beantwortung dieser Fragen von Kulturalisten und Evolutionisten die Rede sein wird, dann freilich nicht im Sinn einer übergeneralisierenden Allaussage über Sozial- bzw. Evolutionswissenschaften. Beide Fächerfamilien sind vielfach ausdifferenziert, und in ihnen arbeiten Kolleginnen und Kollegen, die in ihrer Gesamtheit eine reichhaltige Palette von unterschiedlichen Auffassungen repräsentieren. In bestimmten Forschungsbereichen ist die angesprochene Entzweiung sogar praktisch nahezu bedeutungslos. So weisen neben längst etablierten spieltheoretischen und Rational-Choice-Ansätzen sowie der Verhaltensökonomik durchaus auch stärker kulturalistisch ausgerichtete Ansätze aus dem Bereich der Sozialisationsforschung Schnittstellen zur evolutionären Anthropologie auf (Scheunpflug 2015; Bernardi et al. 2018).

Überhaupt ist in den Sozialwissenschaften in letzter Zeit eine wachsende Aufgeschlossenheit für interdisziplinäre Perspektiven auf die menschliche Natur zu beobachten (Schnettler 2016; vgl. exemplarisch McDermott und Hatemi 2018; Hopcroft 2016; Turner und Maryanski 2015). Insbesondere die Arbeiten von Evolutionsforschern wie Peter Richerson und Robert Boyd (z.B. 2005), vor allem aber Michael Tomasello (z.B. 2014) stoßen neuerdings in weiten Teilen der Sozialwissenschaften 
auf großes Interesse (siehe exemplarisch Albert et al. 2016; Bianchin 2015). Stärker als andere eröffnen diese Autoren Schnittstellen zu sozialwissenschaftlichen Theorien, indem sie die rekursive Kausalbeziehung zwischen Kultur- und Naturgeschichte betonen. Auch die wieder wachsende Bedeutung von Theorien kultureller Evolution kann als Zeichen der Annäherung zwischen den Sozialwissenschaften und der Evolutionären Anthropologie gesehen werden (Mesoudi 2011, 2017).

Solcher Austausch ist aber noch längst nicht die Regel und stößt nach wie vor auf große Verständigungsbarrieren. Diese entstehen für Evolutionisten vor allem im Umgang mit Ansätzen, in denen menschliches Verhalten gleichsam als jenseits aller Natur biologisch funktionslos aufgefasst und soziale Wirklichkeit als kontingente Konstruktion menschlicher Verstandeskraft angesehen wird. Für Kulturalisten entstehen Verständigungsbarrieren vor allem dann, wenn Evos energisch gegen solche Devaluierung von Evolutionsgeschichte und ihrem prägenden Einfluss auf das menschliche Verhalten auch in den kulturell variablen Kontexten der Moderne eintreten. Es geht also im Kern um das Gewicht, das man dem biologischen Evolutionsgeschehen und seinen Implikationen für menschliche Motive, Präferenzen und Strategien in einer Theorie menschlichen Verhaltens beizumessen bereit ist. Ansichten, wonach die Natur des Menschen eine für sozialwissenschaftliche Erklärungen nicht sonderlich nützliche Variable abgibt oder ihre empirische Erforschung gar für unmöglich oder zumindest sinnlos gehalten wird, lassen sich insbesondere in Ansätzen finden, die gemeinhin der Postmoderne zugerechnet werden (etwa Bauman 1995; Rorty 1988), sind aber durchaus nicht auf diese begrenzt, zumal bioskeptische Denkmuster in den letzten Jahrzehnten in den etablierten Wissenskanon der Sozialwissenschaften herabgesunken sind (Brown 2013).

Wenn hier von Kulturalisten die Rede ist, dann sind jedenfalls stets nur diejenigen Wissenschaftlerinnen und Wissenschaftler gemeint, die solche Auffassungen vertreten, und keinesfalls Sozialwissenschaftler in Gänze, ja nicht einmal eine völlig klar definierte und abgrenzbare Gruppe innerhalb der Sozialwissenschaften. Wenngleich dieser Begriff also inhaltlich changiert, wird er sich dennoch als nützlich erweisen, um den Verständigungsschwierigkeiten zwischen Evolutions- und Sozialwissenschaften auf den Grund zu gehen.

Um diese systematisch zu ordnen und zu analysieren, wird wie folgt vorgegangen. In Abschn. 2 werden jene Meinungsbilder und Vorbehalte betrachtet, in welchen sich die Verständigungsprobleme zwischen evolutionärer Anthropologie und kulturalistischen Sozialwissenschaften zeigen. Danach wird in Abschn. 3 in drei Schritten der Frage nachgegangen, woraus sich diese Hemmnisse interdisziplinärer Annäherung speisen. Im ersten Teil dieses Abschnitts wird es um Missverständnisse und Blindstellen gehen, die sich im Grunde leicht ausräumen lassen. Dabei ist vom Vorwurf des Gen-Determinismus zu handeln, des Weiteren von Verwirrungen bei der analytischen Trennung von Sein und Sollen sowie vor allem von der wichtigen, in den Sozialwissenschaften bisher aber kaum bekannten Unterscheidung von ultimaten und proximaten Ursachen. Im zweiten Schritt werden methodologische Konfliktlinien im Zusammenhang mit Populations- und Artvergleichen sowie der Debatte um Emergenz und Reduktionismus in den Blick genommen. Vor diesem Hintergrund können im dritten Schritt jene Gegensätze und Anknüpfungspunkte analysiert werden, die sich angesichts der unterschiedlichen paradigmatischen Grundüberzeu- 
gungen von Evos und Kulturalisten im Zusammenhang mit der Natur/Kultur-Debatte zeigen. Der Schwerpunkt liegt hier auf den verschiedenen anthropologischen Standardmodellen der Disziplinen, auf der Debatte um soziale Konstruktionen sowie auf für die Theoriebildung zentralen Kategorien wie Kultur, Vernunft und Lernen. Im Abschn. 4 wird schließlich darüber berichtet, was zu tun wäre, um die vor Augen geführten Hindernisse interdisziplinärer Theorieintegration zu überwinden.

\section{Was dahinter steckt: Meinungsbilder und Vorbehalte}

Perry und Mace (2010) haben in einer Online-Fragebogenstudie unter Studierenden und Beschäftigten britischer Universitäten Einstellungen zur Bedeutung der Evolutionstheorie für das Verständnis menschlichen Verhaltens erfragt. Durch die wissenschaftliche Expertise der Probanden ließen sich 9,1\% der Varianz in den Antworten erklären. Während erwartungsgemäß Biologen die höchste Akzeptanzrate aufwiesen, sind Sozialwissenschaftler diejenigen mit der höchsten Ablehnungsquote. Selbst Religionswissenschaftler sind nicht so skeptisch, was den wissenschaftlichen Nutzen der Evolutionstheorie für die Humanwissenschaften betrifft. Bemerkenswert ist dieser Befund auch deshalb, weil er die Ergebnisse einer ähnlichen Studie repliziert, die etwa 20 Jahre zuvor durchgeführt wurde (Lieberman 1989). Auf den ersten Blick scheint sich also in den beiden Dekaden, die zwischen diesen Erhebungen liegen, nicht viel getan zu haben, was eine Annäherung von sozialwissenschaftlichen Kulturalisten und biologischen Evolutionisten begünstigt haben könnte.

Ein weiterer Befund aus derselben Studie ist für unser Thema von besonderem Interesse. Die Autoren haben in dem Subsample der Sozialwissenschaftler nach Korrelaten der Ablehnung evolutionärer Ansätze gesucht. Wenig überraschend fanden sie, dass Evolution als Erklärungsmatrix auch für menschliches Verhalten umso eher akzeptiert wurde, je besser das faktische und theoretische Wissen über Evolution war. Die Autoren fanden weiter, dass die Probanden bezüglich des Nutzens der Evolutionstheorie umso skeptischer waren, je länger sie Sozialwissenschaften studiert hatten. Dieser Befund legt nahe, dass die Evolutionsskepsis nachgerade ein „Lehrerfolg“ sozialwissenschaftlicher Ausbildung ist und nicht etwa in erster Linie das Ergebnis eines Selbstselektionsprozesses, in dem sich Evolutionsskeptiker vermehrt für das Studium sozialwissenschaftlicher Fächer entscheiden. Dazu passt auch der mehrfache Befund, dass korrekte Darstellungen des evolutionären Forschungsansatzes in sozialwissenschaftlichen Lehrbüchern noch weitgehend fehlen (Winegard et al. 2014; Leahy 2012; Meißelbach 2019, S. 35 ff.).

Die Gesamtschau einiger weiterer Umfragestudien unter Soziologen und Sozialpsychologen konturiert das Bild jener sozialwissenschaftlichen „Kulturalisten“, bei denen der Austausch mit Evolutionisten an seine Grenzen stößt (Buss und von Hippel 2018; Jonason und Schmitt 2016; Horowitz et al. 2014; Geher und Gambacorta 2010). Grundsätzlich ist in weiten Teilen der Sozialwissenschaften unstrittig, dass Entstehung und Wandel der belebten Natur dem darwinschen Evolutionsalgorithmus unterworfen sind. Jedoch schwächt sich die Zustimmung deutlich ab, wenn diese Einsicht auf das menschliche Gehirn und die Motivationen hinter sozialem Handeln bezogen wird. Die Ablehnung scheint dabei von einem Nexus aus wissenschafts- 
theoretischen und normativen Grundüberzeugungen untersetzt zu sein, wie sie für postmoderne Theorieperspektiven typisch sind.

Solchen Ansätzen liegt eine Wissenschaftsphilosophie zugrunde, die aus Sorge um gesellschaftspolitische Entwicklungen die Außenwirkung wissenschaftlichen Tuns reflektiert. Im Zentrum kritischer Bewertung steht unter anderem die Art und Weise, wie Wissenschaft Politikvorstellungen und Gesellschaftsbilder prägt (Lyotard 1986). Gerade gegenüber der Vorstellung einer „Naturalisierung“ des Menschen (Bauman 1995, S. 20), einer biologisch bestimmten und mithin ,,ahistorischen menschlichen Natur“ (Rorty 1988, S. 11) ist die Skepsis groß. Vielmehr sei ,nichts am Menschen - auch nicht sein Leib - ... fest“" (Foucault 1974, S. 79), er sei schlichtweg „Leib gewordene und Ding gewordene Geschichte“ (Bourdieu 1985, S. 69). In kritischer Absicht wird der analytische Fokus hier auf die - freilich nur kultürliche! Historizität der menschlichen Natur gelegt: Weil jegliche Anthropologien letztlich kontingente soziale Konstruktionen seien, müsse sich gerade angesichts ihrer zentralen Rolle für Gesellschaftstheorien und politische Ideologien von der Idee einer exakt bestimmbaren Natur des Menschen verabschiedet werden.

Schon in den ,sociobiology wars“ schlug Evos aus politisch links stehenden Akademiker- und Aktivistenkreisen der Verdacht entgegen, ihre Forschung sei mit einer konservativen oder gar reaktionären politischen Agenda verbunden (Segerstråle 2000). Und auch eine Forschergeneration nach diesen heftigen Auseinandersetzungen bestehen diese politischen Vorbehalte augenscheinlich fort, wobei es in jüngerer Zeit rhetorisch durchaus etwas leiser zugeht. Das politische Einstellungsprofil von Evolutionsforschern weicht jedoch nicht unterscheidbar von dem der Angehörigen anderer Fächer ab. So stehen etwa US-amerikanische Studierende der Evolutionären Psychologie (Tybur et al. 2007) und Evolutionären Anthropologie (Lyle III und Smith 2012) in ihren politischen Überzeugungen mehrheitlich ebenso links wie Studierende insgesamt.

Nun wäre es ebenso hilfreich wie reizvoll, die Perspektive zu drehen und danach zu fragen, wie sozialwissenschaftliche Forschung bei Evolutionisten angesehen ist. Bedauerlicherweise sind uns hierzu bislang keine Studien bekannt. Möglicherweise gibt es derartige Studien auch gar nicht, weil niemand etwas Brisantes darüber herauszufinden erwartet. Wenngleich Evos den Sozialwissenschaften insgesamt recht unaufgeregt zu begegnen scheinen, gilt dies nicht für die gesamte Spannbreite sozialwissenschaftlicher Projekte. Großes Unverständnis besteht gegenüber radikalkonstruktivistischen und postmodernen Positionen, etwa wenn behauptet wird, dass die Natur des Menschen wegen seiner geistigen Besonderheiten grundsätzlich nicht wissenschaftlich abgebildet werden kann oder dass Erkenntnis viele gleichberechtigte Quellen kennt, unter denen Wissenschaft keine privilegierte Rolle einnimmt (Lyotard 1986; Welsch 1994; s. auch Foucault 1971; Comtesse et al. 2019).

Solche Positionen in den sogenannten ,science wars“, welche die früheren ,,sociobiology wars“ gleichsam auf einer höheren Ebene fortführen, erachten Evos als nachgerade wissenschaftsfeindlich (Carroll et al. 2017; Perry und Mace 2010). Schließlich greifen sie den Wert ihrer eigenen wissenschaftlichen Erkenntnisse ganz grundsätzlich an. Für Evos spielt die Einhaltung wissenschaftlicher Standards eine ganz zentrale Rolle. Sie sehen sich vollkommen dem kritischen Rationalismus 
verpflichtet, der Wert auf evidenzbasierte Interpretationen erhobener Daten legt und wissenschaftlichen Validitätsfragen große Bedeutung beimisst.

All dies vor Augen habend, erscheint die Frontstellung zwischen Evolutionisten und Kulturalisten recht klar umrissen. Sie verläuft keineswegs genau zwischen sozial- und naturwissenschaftlichen Perspektiven auf menschliches Verhalten, sondern entlang methodologischer Grundsatzfragen, die schon innerhalb der Sozialwissenschaften immer wieder für Kontroversen sorgen, wie die jüngste Neuauflage des „Methodenstreits“ in der deutschsprachigen Soziologie erst wieder vor Augen geführt hat (vgl. Esser 2018; Hirschauer 2018). Abseits dieser Fragen scheinen Evos jedoch insgesamt weniger Nachbarschaftsprobleme mit den Sozialwissenschaften zu haben als andersherum - eine interessante Asymmetrie, für die es rekonstruierbare Gründe gibt. Auf diesen Punkt wird im nächsten Abschnitt zurückzukommen sein.

\section{Worum es geht: Die Spannungsfelder}

Woraus genau speisen sich nun diese gegenseitigen Vorbehalte? Wie sich zeigt, lassen sich in mindestens drei Einzelaspekten vermeintliche oder tatsächliche Divergenzen ausmachen, die - wenngleich mit unterschiedlicher Gewichtung - ihrerseits zum interdisziplinären Dialogdefizit beitragen. Diese Aspekte reichen von bloßen Falschauffassungen und unbegründeten Vorbehalten über unterschiedliche methodologische Herangehensweisen bis hin zu paradigmatischen Grundsatzdebatten. Wir beginnen die Erörterung mit den einfachsten dieser „Spaltpilze“, nämlich mit solchen Kontroversen, die nur auf Missverständnissen und Fehlwahrnehmungen beruhen.

\subsection{Alte Irrtümer, Vorbehalte und blinde Flecken}

In Tab. 1 sind diejenigen Aspekte zusammengefasst, die im Grunde schon längst als überwunden gelten könnten. Sie sind in der Literatur vielfach, tiefgreifend und erschöpfend mit dem Ergebnis behandelt worden, dass weitreichender Konsens - auch über die Fakultätsgrenzen hinweg - hergestellt werden könnte. Aber ,nichts ist gefährlicher für neue Wahrheiten als alte Irrtümer" heißt es schon bei Goethe. Und weil dem so ist, müssen wir uns zumindest mit den drei wichtigsten dieser Punkte ein wenig eingehender beschäftigen.

Nach wie vor sorgt die Unterscheidung von proximaten und ultimaten Ursachen menschlichen Verhaltens für große Irritation. Diese in den Sozialwissenschaften weitgehend unbekannte Differenzierung ist für Evolutionisten nämlich von zentraler erkenntnisleitender Bedeutung. In einer viel zitierten Abhandlung hat der für seine Verhaltensforschung mit dem Nobelpreis geehrte niederländische Zoologe Nikolaas Tinbergen (1963) dargelegt, dass eine gute Erklärung für jegliches Verhalten aus Antworten auf vier Fragen bestehen muss:

1. Über welchen Mechanismus wird das Verhalten reguliert; welche Stimuli lösen es aus?

2. Wie bildet sich das Verhalten in der Entwicklung eines Individuums heraus; welche zeitlichen Abfolgen und Umwelteinflüsse sind dabei wichtig (,Ontogenese“)? 
Tab. 1 Alte Irrtümer und blinde Flecken

\begin{tabular}{|c|c|c|}
\hline Irrtum & Kurzkommentar & $\begin{array}{l}\text { Ausführlicher } \\
\text { in }\end{array}$ \\
\hline $\begin{array}{l}\text { Normative Fehl- } \\
\text { schlüsse (,Erklä- } \\
\text { ren ist Rechtfer- } \\
\text { tigen“); Rassis- } \\
\text { mus- und Klas- } \\
\text { sismusvorwürfe } \\
\text { (, Soziobiologie } \\
\text { ist Sozialdarwi- } \\
\text { nismus“) }\end{array}$ & $\begin{array}{l}\text { Diesen Vorwürfen liegen gleich drei Fehler zugrunde: } \\
\text { a) ein falsches Verständnis des Selektionsprinzips, nachdem } \\
\text { natürliche Selektion „,volks-“, „rassen-“ oder ,klassendienliches“ } \\
\text { Verhalten begünstige; } \\
\text { b) eine falsche teleologische Auffassung der Evolution: Das } \\
\text { „Überleben des Tüchtigeren“ wird nicht nur als zwangsläufige } \\
\text { Folge der natürlichen Selektion verstanden, sondern als deren } \\
\text { angeblich angestrebtes Ziel (siehe ,teleologisches Denken“); } \\
\text { c) eine normative Interpretation des „,Selektionsziels“ evolutio- } \\
\text { närer Fitness: ein klassischer „naturalistischer Fehlschluss“ vom } \\
\text { Sein auf das Sollen }\end{array}$ & $\begin{array}{l}\text { Vogel } \\
(1988)\end{array}$ \\
\hline $\begin{array}{l}\text { Teleologisches } \\
\text { Denken (,,Evo- } \\
\text { lution ist Fort- } \\
\text { schritt“) }\end{array}$ & $\begin{array}{l}\text { „Höherentwicklung“ ist keine biologische Kategorie, weil es kei- } \\
\text { nen unabhängigen Maßstab gibt, diese zu messen. „Die biologi- } \\
\text { sche Evolution geht ziemlich langsam nirgendwo hin“ formuliert } \\
\text { Michael Ruse (1995) die teleologiefreie Auffassung von der Ziel- } \\
\text { und Planlosigkeit der Evolution }\end{array}$ & $\begin{array}{l}\text { Mayr } \\
(1988)\end{array}$ \\
\hline $\begin{array}{l}\text { Keine Differen- } \\
\text { zierung zwischen } \\
\text { ultimaten und } \\
\text { proximaten Erklä- } \\
\text { rungen }\end{array}$ & $\begin{array}{l}\text { Wer bei der Erklärung eines Verhaltens nicht zwischen unmittel- } \\
\text { barer Verursachung (,proximate Erklärung“) und biologischer } \\
\text { Funktion (,ultimate Erklärung“) unterscheidet, begeht einen } \\
\text { fatalen Kategorienfehler }\end{array}$ & $\begin{array}{l}\text { Bateson } \\
\text { und Laland } \\
\text { (2013); } \\
\text { Tinbergen } \\
(1963)\end{array}$ \\
\hline $\begin{array}{l}\text { Genetischer De- } \\
\text { terminismus }\end{array}$ & $\begin{array}{l}\text { Häufig gemeint: Entwicklungsprozesse werden ausschließlich } \\
\text { durch Gene reguliert, ohne dass Umwelteinflüsse dabei eine } \\
\text { Rolle spielen. Das ist in der Evolutionsforschung keine breit } \\
\text { akzeptierte Position. Stattdessen gilt: Gene ermöglichen und } \\
\text { regulieren Einflüsse der Umwelt auf Entwicklungsprozesse }\end{array}$ & $\begin{array}{l}\text { Tooby und } \\
\text { Cosmides } \\
\text { (1992) }\end{array}$ \\
\hline $\begin{array}{l}\text { Marginalisierung } \\
\text { der Rolle von } \\
\text { Kultur und Ge- } \\
\text { sellschaft bei } \\
\text { der Erklärung } \\
\text { menschlichen } \\
\text { Sozialverhaltens }\end{array}$ & $\begin{array}{l}\text { Makrophänomene werden von Evos sehr wohl empirisch unter- } \\
\text { sucht und theoretisch gefasst (Beispiele: Theorien der kulturellen } \\
\text { Nischenkonstruktion und der Gen-Kultur-Koevolution) }\end{array}$ & $\begin{array}{l}\text { Laland et al. } \\
(2015) ; \\
\text { Richerson } \\
\text { und Boyd } \\
(2005) ; \\
\text { Odling-Smee } \\
\text { et al. (2003) }\end{array}$ \\
\hline
\end{tabular}

3. Worin liegt die biologische Funktion des Verhaltens, in welcher Weise trägt es zur Lösung von adaptiven Problemen in der Evolution bei (,Anpassungswert“)?

4. Welche Naturgeschichte hat das Verhalten durchlaufen, wie kam es zu seiner evolutionären Entwicklung (,Phylogenese“)?

Die ersten beiden Faktorenbündel werden die proximaten Ursachen eines Verhaltens genannt und bezeichnen seine unmittelbaren „Wirkursachen“. Sie umfassen auch und ganz zentral jene sozialen und kulturellen Einflüsse, denen Menschen situativ ausgesetzt sind (1) und welche sie im Laufe ihrer Sozialisation erfahren haben (2). Die letzten beiden Faktorenbündel sind sogenannte ultimate Ursachen oder „Zweckursachen“. Sie adressieren eine andere Analyseebene, nämlich jene der naturhistorischen Verursachung (3) und der konkreten biophysiologischen Entstehung (4). Wenn beispielsweise Partnerschaftsverhältnisse durch Eifersucht belastet werden, hat das zweifellos vielerlei unmittelbare, also proximate, Ursachen: von einer reaktiven Hormonphysiologie und Persönlichkeitsfaktoren über Besitzmotiva- 
tionen, Konzepte von Ehre und Prestige bis hin zu Geschlechterrollenerwartungen und weiteren kulturell sowie individuell höchst plastischen Faktoren. Eine ultimate Antwort auf die Warum-Frage nach Eifersucht wird demgegenüber auf die adaptive Funktion verweisen, derentwegen sie sich im langen Spiel der natürlichen Selektion durchgesetzt hat: Eifersucht hat sich als psychologischer Mechanismus etabliert, weil sie Individuen zu Verhalten motiviert, das dabei hilft, reproduktive Ressourcen $\mathrm{zu}$ sichern. (Das ist wohlgemerkt eine empirische Erklärung ohne jeglichen normativen Gehalt.)

Weil das Konzept der ultimaten Ursachen unter Sozialwissenschaftlern nicht gebräuchlich ist, missverstehen sie häufig, was gemeint ist, wenn Evolutionisten ein Verhalten mit seiner biologischen Funktion erklären. Sie tendieren irrtümlicherweise dazu, solche ultimaten Erklärungen im Sinne von unmittelbaren Motiven zu interpretieren, also proximat. Allerdings sind eifersüchtigen Individuen die evolutionären Ursachen ihres Gemütszustandes nicht notwendigerweise klar und schon gar nicht nehmen jene in aller Regel den Rang bewusster Handlungsmotivationen ein. Dass ein bestimmtes Verhalten aufgrund von potenzieller reproduktiver Fitnesssteigerung gezeigt wird (,ultimat"), stellt aber keinen Widerspruch zu der Tatsache dar, dass dieses Verhalten auch eine auf den ersten Blick vom evolutionären Hintergrund möglicherweise ganz unabhängig erscheinenden Bedürfnisbefriedigung in einem bestimmten kulturell und sozial geprägten Kontext darstellt (,,proximat“). Die sich proximat ereignenden kausalen Mechanismen laufen dennoch nicht unabhängig von ihren ultimaten Entstehungskontexten ab. Grade und Formen von Eifersucht mögen sich kulturell und interindividuell unterschiedlich darstellen. Der Möglichkeitsraum dieser Variabilität ist aber nicht nur von proximaten, sondern eben auch ganz entscheidend von ultimaten Faktoren geprägt. Ein umfassendes Verständnis von Eifersucht erfordert deshalb die Betrachtung beider Analyseebenen und ihrer Wechselwirkungen.

Wer diese Analyseebenen gewissermaßen ,gegeneinander ausspielt“, begeht einen fundamentalen Kategorienfehler. Dieser führt seitens von Kulturalisten sehr häufig zu maximal fatalen Missverständnissen von Evolutionsforschung. Weil Evos die Unterscheidung von ultimaten und proximaten Erklärungen für Verhaltensweisen ganz routinemäßig nutzen, fällt es ihnen umgekehrt leichter, den (proximaten) sozialwissenschaftlichen Erklärungen mit angebrachtem Verständnis zu begegnen. Damit ist zwar freilich nicht gesagt, dass sie dies auch jederzeit tun. Dennoch liegt hier ein Grund dafür, dass, wie oben angedeutet, Evos mit den Sozialwissenschaften weniger grundsätzliche Probleme haben, als umgekehrt manche Sozialwissenschaftler mit den Evos.

Hartnäckig hält sich auch der Vorwurf des Gen-Determinismus. Geradezu reflexartig wird Evolutionisten von Kulturalisten immer wieder entgegengehalten, sie reduzierten menschliches Sozialverhalten allein auf genetische Ursachen (ausführlich in Crippen 2018). Damit einher gehen häufig Vorhaltungen von Eindimensionalität und unterkomplexem Nachdenken über die soziale Wirklichkeit. Dieser Vorwurf lässt die Evos etwas ratlos zurück, weil für sie nicht ganz klar ist, was damit gemeint sein soll.

Es macht nämlich einen gewaltigen Unterschied, ob man meint, dass (1) die Entwicklung aller organismischen Merkmale auf genetischer Information beruht, 
die durch Vererbung weitergegeben wird, oder dass (2) Unterschiede in den Merkmalen notwendigerweise mit genetischen Unterschieden einhergehen müssten. In Bezug auf (1) sind Evos in der Tat genetische Deterministen und dies aus guten Gründen. Auch das durch drückende Schuhe proximat erworbene Hühnerauge hat natürlich eine genetische Grundlage - und folglich eine ultimate Ursache. In Bezug auf (2) sind sie es jedoch nicht. Wer unter einem Hühnerauge leidet, muss sich nicht notwendigerweise genetisch von jenen unterscheiden, denen dieses Leid unbekannt ist.

Allgemeiner formuliert: Die lokale Einnischung von Organismen in ihren sozioökologischen Lebenskontext - Elias oder Bourdieu würden es Habitualisierung nennen - erfolgt regelhaft über evolvierte Reaktionsnormen in der Form von konditionalen Entwicklungs- und Verhaltensstrategien. Wie sie sich entfalten, hängt davon ab, wie der Organismus seine Umwelt erfährt. Diese Umwelt informiert den Organismus, welche Entwicklungsoption hier und jetzt funktional sein dürfte; und so können gleiche Genotypen durchaus unterschiedliche Phänotypen hervorbringen. Allerdings: Einnischung ist letztlich genauso genetisch reguliert wie jeder andere organismische Prozess. Der Determinismus-Vorwurf wäre nur dann gerechtfertigt, wenn Evos eine durchgängig umgebungsunsensible Eins-zu-eins-Relation zwischen Gen und Merkmal unterstellen würden. So einfach funktioniert Genetik aber nicht und Evos denken so auch nicht.

Auch im Hinblick auf das Verhältnis von Erklärungen und Bewertungen führen verbreitete Fehlwahrnehmungen zu ganz unnötigen Verständigungsschwierigkeiten. Wenn es um evolutionäre Theorien menschlichen Verhaltens geht, gerät nämlich immer wieder ein weithin akzeptiertes wissenschaftstheoretisches Diktum in Vergessenheit: Erklären ist nicht Rechtfertigen! Wer sich - wie manche Evos - den evolutionären Hintergründen von politisch sensiblen Phänomenen widmet, muss befürchten, dass Teile des sozialwissenschaftlichen Publikums diese Differenzierung nicht mehr uneingeschränkt vollziehen. Dabei sollte doch klar sein, dass die ergebnisoffene Erforschung der biologischen Funktionalität von Geschlechtsunterschieden in keiner Weise Sexismus rechtfertigt. Und auch Gewalt, Rassismus, Despotismus oder soziale Ungleichheit werden nicht dadurch moralisch legitimiert, dass man nach ihren evolutionär-anthropologischen Ursachen sucht (und sie auch findet). Das gilt übrigens auch für Barmherzigkeit, empathische Solidarität oder gemeinschaftsdienliche Heldenhaftigkeit.

Sein und Sollen sind eben zwei verschiedene Dinge. Wer diese auf David Hume zurückgehende Unterscheidung ignoriert, begeht Fehlschlüsse in zwei Varianten: Vom Sein auf das Sollen zu schließen, ist ein naturalistischer Fehlschluss; und vom Sollen auf das Sein zu folgern, nennt man einen moralistischen Fehlschluss. Evolutionisten standen immer schon im Verdacht, anfällig für naturalistische Fehlschlüsse zu sein - und dies zugegebenermaßen keineswegs durchweg unbegründet. Insbesondere das Werk von Konrad Lorenz (z.B. 1963) ist durchzogen von Argumenten für eine Ableitung des Sollens aus dem Sein. Was evolutionär angepasst ist, war in seiner Sicht gut und richtig. Für ihn war die Natur eine moralische Lehranstalt und Gemeinschaftsdienlichkeit ihr erstes Gebot. Dieser Fehlschluss war in der Form des Sozialdarwinismus von Herbert Spencer auch in die moderne Sozialtheorie schon früh eingedrungen, einer wohlgemerkt soziologischen Fehlrezeption darwinschen 
Denkens. In letzter Konsequenz diente er dann den rassistischen Auswüchsen des 20. Jahrhunderts als eine Legitimationsgrundlage - mit drastischen Folgen für die weitere Rezeption evolutionärer Erklärungen in den Sozialwissenschaften.

Seit dem Paradigmenwechsel der modernen Biologie (der sogenannten „Hamiltonschen Wende“) hin zu einer genzentrierten Auffassung vom evolutionären Geschehen gilt biologische Evolution nicht mehr als ein irgendwie art- oder gemeinschaftserhaltendes Prinzip. Stattdessen handelt es sich um einen zielblinden Prozess der differenziellen Reproduktion genetischer Information, mit dessen Sein sich gesellschaftstheoretische Sollensaussagen nicht rechtfertigen lassen. Evolutionstheorie ist völlig agnostisch gegenüber dem normativen Wert biologischer und sozialer Phänomene; sie bietet nicht mehr und nicht weniger an als deren (ultimate) Erklärung. Evolutionisten haben aus ihrer Geschichte gelernt und diese Lektion verinnerlicht. Man wird heute lange suchen müssen, bevor man auf einen naturalistischen Fehlschluss in seriöser Evo-Literatur stößt.

Moralistischen Fehlschlüssen im Zusammenhang mit evolutionären Erklärungen ist hingegen eher in einigen Bereichen der Sozialwissenschaften zu begegnen. Dort ist gelegentlich die Tendenz zu beobachten, solche Theorien abzulehnen, wenn sie nicht $\mathrm{zu}$ angestrebten gesellschaftlichen Zuständen zu passen scheinen (Schnettler 2016): Gleichheit, Willensfreiheit, Vernunft, Gemeinwohl. Solchen historisch zu einem Gutteil in der philosophischen Aufklärung wurzelnden emanzipatorischprogressiven Idealen liegt die Vorstellung weitestgehender kultureller Formbarkeit menschlichen Verhaltens zugrunde, weshalb Evo-Forschung zu ihrer Befeuerung vermeintlich nicht viel beizutragen vermag. Es ist aber nicht zu erkennen, wem damit gedient sein sollte, aufgrund normativer Vorbehalte die Ergebnisoffenheit empirischer Wissenschaft zu beschneiden. Schließlich steigert doch gerade ein zutreffendes Verständnis der Wirklichkeit deren erfolgreiche Manipulation in die Richtung erwünschter Ziele. Anders gewendet: Tatsächliche Zielverwirklichung wird davon abhängen, wie zutreffend die zugrundeliegenden anthropologischen Annahmen waren. Wenn Evos diesbezüglich in der Rolle von „Spaßbremsen“ auftreten, sollte das nicht als politisch grundierter Gegenwind aufgenommen werden, sondern als Einladung zum produktiven wissenschaftlichen Dialog.

Nach wie vor mögen also die mangelnde Unterscheidung zwischen proximaten und ultimaten Ursachen, das häufig verquere Determinismus-Argument sowie Verwirrungen im Sein/Sollen-Verhältnis zu schädlichen Irritationen führen. Gleiches gilt auch für die anderen in Tab. 1 aufgeführten Irrtümer und Vorbehalte, etwa die weiter unten noch knapp zu diskutierende Vorstellung, evolutionäre Erklärungsmodelle vernachlässigten den Kausalfaktor Kultur. Die fortgesetzte Diskussion all dieser Punkte lohnt allerdings kaum, solange keine einschlägigen neuen Einsichten vorgelegt werden können. Die alten Irrtümer und blinden Flecken sind als solche gut erkannt und werden von den Gutwilligen längst umgangen. Wer im interdisziplinären Diskurs dennoch aus dem Pool dieser Argumente schöpft, ist entweder intellektuell faul oder betreibt strategische Feindbildpflege. 
Tab. 2 Methodologische Konfliktlinien zwischen Kulturalisten und Evolutionisten

\begin{tabular}{lll}
\hline Thema & Handhabung durch Kulturalisten & Handhabung durch Evos \\
\hline $\begin{array}{l}\text { Populations- } \\
\text { und }\end{array}$ & $\begin{array}{l}\text { Konzentration auf Homo sapiens, } \\
\text { dort meist fokussiert auf }\end{array}$ & $\begin{array}{l}\text { Wertgeschätzt als Instrument der Theo- } \\
\text { riebildung }\end{array}$ \\
Reduktionismus & WEIRD-Populationen & \\
& $\begin{array}{l}\text { Kritische Distanz zu reduktionistischen } \\
\text { Erklärungen für soziale Tatsachen }\end{array}$ & $\begin{array}{l}\text { Starker Fokus auf reduktionistische } \\
\text { Erklärungen sozialer Tatsachen }\end{array}$ \\
& $\begin{array}{l}\text { Theoretisch akzeptiert und breit disku- } \\
\text { tiert, forschungspraktisch für die Er- } \\
\text { klärung sozialer Tatsachen als wertvoll } \\
\text { erachtet }\end{array}$ & $\begin{array}{l}\text { Theoretisch zwar akzeptiert, for- } \\
\text { schungspraktisch im Hinblick auf so- } \\
\text { ziale Emergenzphänomene jedoch von } \\
\text { geringem Stellenwert }\end{array}$ \\
\hline
\end{tabular}

\subsection{Methodologische Konfliktlinien}

Lohnender als die Beschäftigung mit bloßen sachlichen Irrtümern ist die Analyse jener methodologischen Aspekte, die von Kulturalisten und Evolutionisten sehr unterschiedlich verstanden und gehandhabt werden. In Tab. 2 sind diejenigen zunächst wieder ganz schemenhaft knapp umrissen, welche es im Folgenden näher zu beleuchten gilt, weil sie interdisziplinäre Kontroversen besonders befeuern.

Der Zweifel an der wissenschaftlichen Legitimität des Tier/Mensch-Vergleichs, wenngleich freilich längst nicht von allen Kulturalisten gehegt, ist einer der sichtbarsten Kritikpunkte an evolutionären Perspektiven auf die menschliche Natur. Sozialwissenschaftler befassen sich naturgemäß nahezu ausschließlich mit Menschen; und abgesehen von Kulturanthropologen fokussieren die meisten von ihnen dabei vorwiegend auf sogenannte WEIRD-Populationen - „western, educated, industrial, rich, democratic" (Henrich et al. 2010). Vergleiche mit traditionalen, vormodernen Gesellschaften oder gar Artvergleiche kommen hingegen nur überaus selten vor. Wenngleich Sozialwissenschaftler eine reichhaltige Tradition haben, Subgruppen innerhalb von Gesellschaften etwa in Hinblick auf soziale und materielle Benachteiligungen von Minderheiten miteinander zu vergleichen, so spielt sich das oft nur im Kontext moderner und meist entwickelter Gesellschaften ab. Einesteils dürfte das in der schieren Datenverfügbarkeit begründet liegen. Andernteils spielen historische Faktoren eine Rolle, denn schließlich waren die Sozialwissenschaften dereinst als Reaktion auf die Problemlagen gerade dieser Gesellschaften entstanden. Und nicht zuletzt ist dies eben eine Konsequenz des Umstands, dass es kaum Sensibilität für die zwei ultimaten der vier Tinbergen-Fragen gibt. Wer von vornherein die naturgeschichtlichen Ursachen für Verhalten ausklammert (Phylogenese, Anpassungswert), braucht freilich Tier/Mensch-Vergleiche nicht zu praktizieren.

Doch wie rechtfertigt das eine häufig feindselige Grundeinstellung gegenüber den evolutionären Verhaltenswissenschaften, zu deren unverzichtbarem Kerngeschäft Tier/Mensch-Vergleiche nun einmal gehören? Provokant ließe sich fragen, ob hier vielleicht, letztlich in Fortführung christlicher Auffassung, eine Fernwirkung jenes frühen evolutionären Denkens sichtbar wird, das den Homo sapiens als „Krone der Schöpfung“" stilisiert und ihn so gleichsam narzisstisch gegen jeglichen Tiervergleich immunisiert hat? Als Krone der Schöpfung galt freilich immer nur der Mensch der eigenen, selbstverständlich überlegen gedachten Gesellschaft. Gemäß 
dieser Tradition spielt neben einer Angst vor Biologismus möglicherweise auch eine anthropozentrische Eitelkeit ihre Rolle bei der Aufrechterhaltung der Idee von der unvergleichlichen und unvergleichbaren Sonderstellung des Menschen - sekundiert von einem Chauvinismus, welcher der eigenen Gesellschaft wie selbstverständlich einen zivilisatorisch erhöhten Status zuweist.

Gegen diese Entgegnung auf die Kritik an weitgespannten Arten- und Populationsvergleichen dürften gerade postmoderne Kulturalisten im Grunde wenig einzuwenden haben, ist doch auch ihnen der westliche Ethnozentrismus in den (Sozial-)Wissenschaften ein Dorn im Auge. Ironischerweise fällt somit der Vorwurf, nur ,just-so-stories“ zu produzieren, nicht selten gerade auf denjenigen Fachbereich zurück, aus dem heraus er geäußert wird. Schließlich liefern Untersuchungen an WEIRD-Populationen aus Sicht der Evos nur einen einzigen Datenpunkt auf dem anthropologischen Gesamttableau und, wie Henrich et al. (2010) anhand mehrerer Verhaltensbereiche zeigen, nicht einmal für Homo sapiens einen sonderlich repräsentativen.

Mehr noch: Möglicherweise liegt in dieser Vergleichsaversion sogar die Wurzel der viel diskutierten und auch schon oft problematisierten (Lopreato und Crippen 1999) Eigenheit der Sozialwissenschaften begründet, als ,multiparadigmatische Disziplinen“ eine kaum überschaubare Theorievielfalt zu beherbergen. Schließlich sind anthropologische Prämissen theoriekonstruktiv höchst wichtige Bestandteile sozialwissenschaftlicher Erklärungen. Gerade diese Theoriebestandteile nicht durch vergleichende Analyse der eigenen Vergemeinschaftungsformen auf eine breitere empirische und theoretische Basis stellen zu können, verschließt Potenziale für theoretisches Weiterkommen, etwa durch das Aussondern von als falsch erwiesenen Ursachenvermutungen.

Natürlich kommen auch Evolutionisten keineswegs ohne singuläre Beobachtungen und Spekulation aus. Doch als kritische Rationalisten weisen sie einer unbewiesenen Behauptung oder der mutigen Verallgemeinerung eines singulären Befundes stets nur einen eng begrenzten Stellenwert zu. Solche Spekulationen sind in der Wissenschaft als Quelle zur phantasievollen Hypothesenbildung hochgradig willkommen, vorausgesetzt allerdings, den Hypothesen passiert das, wozu sie da sind: eine seriöse Überprüfung. Kritikwürdig ist freilich, wenn ,,just-so-stories“ subtil in die Erklärung sozialer Phänomene „hineingeschmuggelt“ und dann als Tatsachen behandelt werden. Aber vor solchem Fehlverhalten ist keine Disziplin gefeit.

Den Verständigungsbarrieren rund um das Verhältnis von Emergenz und Reduktionismus ist ungleich schwieriger beizukommen. Systematisch geht es hier um die Frage, ob sich Phänomene auf höheren Organisationsebenen der Wirklichkeit allein durch die Erforschung von Aktion und Interaktion auf der niedrigeren Ebene ergründen und erklären lassen. Im Konkreten stellt sich die Frontstellung, grob überzeichnet, häufig wie folgt dar: Sozialwissenschaftler haben Evos im Biologismus-Verdacht, weil sie aufgrund ihrer reduktionistischen Forschungsstrategien die emergente Eigenlogik sozialer Wirklichkeit, und damit das Wesentliche an spezifisch menschlicher Vergemeinschaftung, ausblendeten. Andersherum wittern Evolutionäre Anthropologen einen ,kulturalistischen Reduktionismus“: Weil sich Sozialwissenschaftler zu wenig für biopsychologische Tiefenschichten sozialen Handelns interessierten, hingen ihre emergentistischen Theorien gleichsam ,,in der Luft“. 
Allerdings werden solche vereinfachenden Vorstellungen dem tatsächlichen Diskussionsstand in beiden Forschungssträngen ebenso wenig gerecht wie der Komplexität des Gegenstands selbst (Greve und Schnabel 2011; Opp 2014; Meißelbach 2018). Als Aggregations- oder Mikro-Makro-Problem wird er in den Sozialwissenschaften seit langem kontrovers diskutiert; und handlungstheoretische Mikrofundierung spielt in diesen Debatten regelmäßig eine zentrale Rolle. Andersherum wird das Bestehen von organismischen Emergenzphänomenen auch von den evolutionären Humanwissenschaften nicht bestritten. Schließlich gehört das Leben selbst dazu. Einigkeit besteht ferner darüber, dass menschliche Vergesellschaftung komplexe Makrophänomene hervorbringt, die - einmal aus interindividuellen Interaktionen erwachsen - erhebliche strukturierende Kraft auf ihre Teile ausüben. Allerdings zögern Evos, solche komplexen Systeme als Emergenzphänomene im engeren Sinne zu bezeichnen.

Hier ist sicherlich noch viel Verständigungs- und Begriffsarbeit zu leisten. Als Ausgangspunkt dafür kann eine einfache methodologische Heuristik dienen, nämlich die pragmatische Unterscheidung von gutem und schlechtem Reduktionismus (Slingerland 2008). „Guter“ Reduktionismus leitet aus den komplexen Verschränkungen der verschiedenen Organisationsebenen des Lebendigen einerseits die Aufgabe interdisziplinär arbeitsteiliger Forschung samt Theorien- und Methodenpluralismus ab, andererseits die Notwendigkeit, die empirischen Erkenntnisse über Mikro-MakroWechselwirkungen auf verschiedenen Komplexitätsebenen zu einem möglichst konsistenten Gesamtbild zusammenzufügen. „Schlechter“ Reduktionismus trifft hingegen eine methodologische Vorfestlegung auf bestimmte Analyseebenen und blendet andere aus, nicht selten nur auf der Grundlage von kontingenten Disziplinen- oder Paradigmengrenzen. Wer dergestalt etwa an einer emergenten „Besonderheit des Sozialen“ paradigmatisch festhielte, fiele, wie im Folgenden genauer zu zeigen sein wird, schlimmstenfalls einem „kulturalistischen Kreationismus“ anheim.

\subsection{Unterschiedliche paradigmatische Grundüberzeugungen}

Im Verlauf der Disziplingeschichten hat sich in den verschiedenen humanwissenschaftlichen Fächern eine Reihe von Grundüberzeugungen derart verfestigt, dass sie faktisch paradigmatischen Charakter angenommen haben. Sie sind gleichsam die Navigationsgerätschaften, mit deren Hilfe Exkursionen in wissenschaftlich zu erkundendes Neuland ihren Anfang nehmen. Diese Grundüberzeugungen sind selbst nur selten Gegenstand wissenschaftlicher Überprüfung - sei es, weil sie vielen als a priori evident und unumstößlich gelten, oder weil sie an objektive Grenzen der Überprüfbarkeit stoßen. In jedem Fall kanalisieren sie den weiteren Gang der Forschung. In der Summe bilden die Grundüberzeugungen von Evolutionisten und Kulturalisten zwei sehr unterschiedliche epistemische Landkarten. In Tab. 3 sind einige prominente Markierungen dieser beiden intellektuellen Landschaften zusammengestellt.

In allen vier Aspekten der Tab. 3 spiegelt sich letztlich die Jahrhundertdebatte um das Verhältnis von Natur und Kultur. Aus evolutionärer Sicht hat sie längst ihre Brisanz verloren, seit sich die Einsicht durchgesetzt hat, dass Natur und Kultur nicht additiv in ihrem Einfluss auf menschliches Verhalten gedacht werden können, 
Tab. 3 Paradigmatische Grundüberzeugungen von Kulturalisten und Evolutionisten

\begin{tabular}{|c|c|c|}
\hline Thema & Kulturalisten & Evolutionisten \\
\hline $\begin{array}{l}\text { Anthropologi- } \\
\text { sches Stan- } \\
\text { dardmodell }\end{array}$ & $\begin{array}{l}\text { Kulturalistisches Standardmodell: } \\
\text { Die Natur des Menschen ist im We- } \\
\text { sentlichen konstant und/oder ganz } \\
\text { unbestimmt. Variabilität in der sozia- } \\
\text { len Praxis ist kulturell und historisch } \\
\text { kontingent und kann deshalb nicht } \\
\text { naturalistisch erklärt werden }\end{array}$ & $\begin{array}{l}\text { Evolutionäres Standardmodell: Die Evolu- } \\
\text { tion produziert variable Phänotypen nach } \\
\text { Maßgabe einer adaptiven Selektionsge- } \\
\text { schichte. Dies gilt auch für das menschliche } \\
\text { Denken, Fühlen und Handeln. Variabilität } \\
\text { in der sozialen Praxis ist deshalb Ausdruck } \\
\text { der Natur des Menschen }\end{array}$ \\
\hline $\begin{array}{l}\text { Konstruktivis- } \\
\text { mus }\end{array}$ & $\begin{array}{l}\text { Teils radikaler (ontologischer) Sozial- } \\
\text { konstruktivismus: Emotionen, Normen, } \\
\text { Rollen usw. sind (mehr oder weni- } \\
\text { ger) vollständig sozial konstruiert und } \\
\text { werden dem Individuum „von außen“ } \\
\text { aufgeprägt }\end{array}$ & $\begin{array}{l}\text { Moderater epistemischer Konstruktivismus: } \\
\text { Emotionen, Werte usw. entstehen - wie } \\
\text { jede Form von Bedeutung - nur innerhalb } \\
\text { individueller Gehirne. Soziale Konstruk- } \\
\text { tionsprozesse verlaufen in den Bahnen } \\
\text { evolvierter Regelhaftigkeit }\end{array}$ \\
\hline $\begin{array}{l}\text { Soziales } \\
\text { Lernen, } \\
\text { Traditions- } \\
\text { bildung und } \\
\text { „kulturelle } \\
\text { Evolution“ }\end{array}$ & $\begin{array}{l}\text { „Kultur statt Gene“: Eigenständige } \\
\text { soziale Tatsachen legen sich über die } \\
\text { genetische Natur des Menschen }\end{array}$ & $\begin{array}{l}\text { „Kultur durch Gene“: Die menschliche Na- } \\
\text { tur ermöglicht Kultur und steht mit ihr in } \\
\text { ultimaten sowie proximaten Wechselwir- } \\
\text { kungen }\end{array}$ \\
\hline $\begin{array}{l}\text { Metaphysik } \\
\text { des Geistes }\end{array}$ & $\begin{array}{l}\text { Dualismus/Idealismus: Gehirn } \neq \text { Geist; } \\
\text { Vernunft schiebt die Grenzen des } \\
\text { Machbaren weit hinaus, großer Mach- } \\
\text { barkeitsoptimismus }\end{array}$ & $\begin{array}{l}\text { Monismus/Naturalismus: } \\
\text { Gehirn = Geist; Rationalitätsskepsis, enge } \\
\text { Grenzen des Machbaren }\end{array}$ \\
\hline
\end{tabular}

sondern nur synergetisch. Seit Kultur aus der Natur hervorgebracht wurde, prägen und bedingen beide einander gegenseitig und lassen sich nicht in unabhängige Kausalfaktoren auftrennen. Alle Dichotomien, die diese Einsicht missachten (etwa „angeboren versus erworben“, „genetisch versus erlernt“ oder „,biologisch versus sozial") sind vom Ansatz her irreführend und deshalb letztlich unbrauchbar (Tooby und Cosmides 1992; Laland et al. 2015). „Genes allow the environment to influence the development of phenotypes“, so bringen Cosmides und Tooby (1997) auf den Punkt, warum für Evolutionsforscher die Kultur kein Gegensatz zur Biologie ist, sondern gleichsam deren Fortsetzung mit anderen Mitteln. Unter Sozialwissenschaftlern ist hingegen die Auffassung noch weit verbreitet, dass Kultur einen von natürlichen Grundlagen ganz unabhängigen Effekt auf menschliches Verhalten hat.

Für unser Thema ist an dieser Debatte im Grunde nur ihr Niederschlag in zwei verschiedenen anthropologischen Standardmodellen wichtig. Aus den beiden Polen des Natur/Kultur-Dualismus erwachsen nämlich zwei gegensätzliche Bewertungen von menschlichen Verhaltensunterschieden und den Gründen ihrer Genese. Das „kulturalistische Standardmodell“ sieht die Natur des Menschen als im Wesentlichen konstant an. Weil Variabilität in der sozialen Praxis kulturell und historisch kontingent sei, könne sie gar nicht mit der Natur des Menschen erklärt werden. Demgegenüber gründet das ,evolutionäre Standardmodell“ auf dem Umstand, dass die Evolution selbst variable Organismen hervorbringt, weil gerade phänotypische Flexibilität entscheidende Selektionsvorteile bringt. Variabilität in der sozialen Praxis sowie im menschlichen Denken, Fühlen und Handeln sei gerade Ausdruck dieser biologischen Angepasstheit. 
Damit sind zwei deutlich unterschiedliche Sichtweisen auf die Natur des Menschen benannt. Das kulturalistische Standardmodell fördert eine essenzialistische, universalistische Sicht auf den Menschen, in der die Rede von der „menschlichen Natur" entweder eine varianzarme natürliche Gleichheit oder völlige Unbestimmtheit aller Menschen meint. Evos betonen hingegen die natürliche Unterschiedlichkeit der Menschen innerhalb eines angebbaren Möglichkeitsraums. Sie verweisen u.a. auf die frequenzabhängige Wirkweise der natürlichen Selektion, die ganz zwangsläufig zu einer mehr oder weniger ausgeprägten genetischen Populationsdifferenzierung führt, beispielsweise gut untersucht in der Evolutionsgenetik von Persönlichkeitsunterschieden (Penke et al. 2007). Darüber hinaus können Verhaltensunterschiede häufig als Ausdruck biologisch evolvierter, konditional wirkender Verhaltensstrategien verstanden werden, ohne dass dabei genetische Unterschiede eine Rolle spielen müssten.

Eine weitere paradigmatische Entzweiung gerade zwischen Kulturalisten und Evolutionisten zeigt sich in der Konstruktivismusdebatte. Mit der Rede von ,sozialen Konstruktionen“ ist im sozialwissenschaftlichen Schrifttum häufig die Grundüberzeugung verbunden, dass Emotionen, kulturelle Normen, soziale Rollen (insbesondere Geschlechterrollen), Transzendenzvorstellungen usw. nicht ,an sich“ bestehen, sondern gesellschaftlich gemacht sind. ,Unsere Ideen, Werte, Handlungen, sogar unsere Emotionen sind, wie selbst unser Nervensystem, kulturelle Erzeugnisse“ (Geertz 1973, S. 50, Übersetzung d. A.). Diese Sichtweise folgt dem von Durkheim (1961) formulierten Postulat von der Autonomie des Sozialen und impliziert augenscheinlich die Vorstellung, Menschen würden mit einem mehr oder weniger inhaltsleeren Gehirn - also: als „tabula rasa“ - geboren, das nur von Quellen außerhalb des Individuums inhaltlich strukturiert und gefüllt wird (Pinker 2003).

Evos können sich dem nur zum Teil anschließen, denn aus ihrer Sicht bleibt eine weitergehende naturhistorische Frage unbeantwortet: Wenn die Kultur den Menschen macht, wer hat dann die Kultur gemacht? Zwar ist schon richtig, dass Menschen die Konstrukteure ihrer kulturellen Umwelten sind und dass dabei intersubjektive Verständigung eine zentrale Rolle spielt. (Wir kommen darauf gleich zurück.) Jedoch wird sich eine überzeugende Erklärung des Ablaufens dieser Prozesse immer auch auf anthropologische Argumentationen stützen und mithin den natürlichen Grundlagen des Sozialen Rechnung tragen müssen.

Für Evos sind radikalkonstruktivistische Theorien der Hervorbringung sozialer Wirklichkeit deshalb letztlich eine Spielart kreationistischen Denkens. Solcher ,kulturalistischer Kreationismus“ ähnelt nämlich formal durchaus dem religiösen Kreationismus. Beide beinhalten den dogmatischen Abbruch der Suche nach natürlichen Ursachen durch ziemlich willkürliche Setzung eines Anfangs: Kultur und Gesellschaft hier, Schöpfergott dort. Beides ist letztlich gleichermaßen antievolutionär und konvergiert - ironischerweise, wie Richter (2005) anmerkt - in einer unheilvollen Allianz: ,Solange die Soziologie an der Trennung menschlichen Verhaltens von der Evolution festhält, sieht sie sich einem peinlichen Dilemma gegenüber: Wenn sie soziale Prozesse nicht auf der Basis natürlicher evolutionärer Prinzipien erklären will, muss sie zum Gedanken der besonderen Schöpfung des Menschen zurückkehren, gleichgültig, welche Verkleidung sie dafür wählt“" (Baldus 2002, S. 239). 
Evos bezweifeln keineswegs, dass Sinn und Bedeutung konstruiert sind. Aufgrund der Einsichten von Hirn- und Bewusstseinsforschung steht für sie fest, dass alles Bedeutungsbeladene, eben Werte, Emotionen, soziale Rollen, Transzendenzvorstellungen usw., außerhalb des Bewusstseins nicht irgendwie materiell vorhanden ist. Bedeutung entsteht nur im Gehirn, und zwar in jedem einzelnen neu; Gedanken werden in jedem Gehirn separat konstruiert, wenn sie gedacht werden. Die Regiezentrale für soziale Konstruktionsprozesse liegt also nicht außerhalb, sondern innerhalb jedes individuellen Bewusstseins. Sie besteht aus jenen evolvierten kognitiven Prozessen, die unseren Weltzugang strukturieren und überhaupt erst ermöglichen. Jeder ist der Konstrukteur seiner eigenen Erlebenswelt. In der „Welt da draußen“ gibt es weder Farben, noch Töne, keinen Stress und keine Euphorie, keine Schönheit und keine Hässlichkeit, weder Freiheit noch Gerechtigkeit, ja nicht einmal Wahrheit.

Allerdings folgt daraus nicht, dass die „Welt da draußen“ nicht existiere, so jedenfalls die metaphysische Grundüberzeugung, die Evos auch mit den meisten Sozialwissenschaftlern teilen. Die geophysikalische Struktur der Erde, das Leben in seinen überaus vielfältigen Formen, einschließlich seiner biologischen und sozialen Differenzierung, all das ist real vorhanden. In dieser Wirklichkeit manifestieren sich auch die ganz realen Folgen jener Handlungen, welche Menschen auf der Grundlage ihrer jeweiligen Situationsdefinitionen (also: ihrer Wahrnehmungen, Sinn- und Bedeutungszuweisungen) vornehmen, ganz unabhängig von deren subjektiver Konstruktion. Diese letztlich nur das in den Sozialwissenschaften wohlbekannte ,Thomas-Theorem“ wiedergebende Auffassung umreißt einen Sozialkonstruktivismus, der mit einem ontologischen Realismus vollständig kompatibel ist.

Allerdings sind nach Auffassung von Evolutionisten auch die grundlegenden Regeln und kausalen Mechanismen von in ihren Ergebnissen hoch variablen sozialen Konstruktionsprozessen ihrerseits gemäß ihrer ultimaten Nützlichkeit biologisch evolviert und letztlich genetisch festgelegt, gehören also zur menschlichen Natur. Sie sind deshalb weder verfügbar noch verhandelbar. In diesem Sinn stehen für Evos auch Werte, Emotionen, soziale Rollen, Transzendenzvorstellungen usw. in dringendem Verdacht, eine biopsychologische Grundlage zu haben, deren proximatkonditionale Flexibilität und Plastizität auf ihren ultimaten Anpassungswert zurückgeht.

Entgegen einer unter Kulturalisten verbreiteten Intuition stehen soziales Lernen und kulturelle Tradierung deshalb nicht im Gegensatz zu einer evolutionären Interpretation der menschlichen Natur. Im Gegenteil, Lernen ist eine evolvierte Kompetenz, die sich in der natürlichen Selektion gerade deshalb bewährt hat, weil sie im Mittel adaptive Vorteile bot, etwa wenn bewährte fitnesssteigernde Verhaltensweisen weitergegeben werden konnten. Lernen befreit nicht von der „Diktatur der Gene“, sondern exekutiert sie auf besondere Weise. Die psychosoziale Kausalmechanik menschlichen Lernens lässt sich deshalb auch in evolutionärer Perspektive besonders gut verstehen (Henrich und McElreath 2003; Voland 2006). Gleiches gilt für durch Lernen tradierte und institutionell verfestigte Kultur. Sie bietet vielfältige genetische Fitnessdividenden, etwa als „Aufbewahrungsort“ nützlicher Ideen, als gemeinsamer Referenzrahmen für intersubjektive Verständigung und kollektives Handeln oder gleichsam als Puffer zwischen Menschen und den Fährnissen ihrer natürlichen Umwelt (Eibl 2009). 
Für Evos gilt also nicht „Kultur statt Gene“, sondern „Kultur durch Gene“. Gleichwohl verdienen kulturelle Transmissionsbahnen besondere Beachtung. Mit der „extended evolutionary synthesis“ (Laland et al. 2015) steht eine moderne Offerte der Evolutionstheorie zur Verfügung, die Konstruktion, Transmission und Wandel von Kultur in Zusammenhang mit der klassischen Evolutionstheorie bringt. Bei Anspruch auf gleiche Erklärungsleistung wie einschlägige sozialwissenschaftliche Theorien hat sie einen viel breiteren Geltungsbereich, denn sie schließt kulturfähige Tiere, wie vor allem Primaten, Wale, Delfine und langlebige Vögel, mit ein. Von ihnen liegen zudem, ebenso wie von Menschen, konkrete Untersuchungen über das rekursive Verhältnis vor, in dem arttypische kulturelle Gegebenheiten mit Genfrequenzverschiebungen stehen (Whitehead et al. 2019).

Wenig spricht vor diesem Hintergrund dafür, dass die Menschheitsentwicklung eine Geschichte der Emanzipation von biologischen Zwängen sei. Evos finden deshalb auch die Mängelwesen-Idee wenig stichhaltig, wie sie seit Herder in der Philosophie gepflegt wird und von dort auch in die Sozialwissenschaften ausgestrahlt hat. Nach ihr ist Kultur, in Marquards (1974) sprachwitziger Façon, eine „Inkompetenzkompensationskompetenz" des Menschen als „Sitzenbleiber der Evolution“. Es ist jedoch weder theoretisch einleuchtend noch empirisch darstellbar, dass heutige Gesellschaften den biologischen Imperativ bezwungen haben sollten - auch nicht mit den Mitteln des Gehirns, dieses so leistungsstarken evolvierten Lernorgans.

An dieser Stelle münden Diskussionen unweigerlich in Reflexionen zur Metaphysik des Geistes. Wenngleich die Behandlung dieses Themas hier essayistisch bleiben muss, erscheinen einige abschließende Anmerkungen dazu doch zielführend. Denn obwohl das Verhältnis von Biologie und Sozialem inzwischen viel besser verstanden ist als noch vor einigen Jahrzehnten, reichen auch die Wurzeln der Natur/Kultur-Debatte noch immer bis hinter die Grenzen unseres derzeitigen Wissens. Und so führt der Diskurs letztlich doch immer wieder zurück auf metaphysische Grundannahmen, die verschiedenen Strängen humanwissenschaftlicher Forschung, möglichweise zum Preis der Selbsttäuschung, Sicherheit verleihen, obwohl die „Anfänge von allem“ hinter einer epistemischen Nebelwand unerkannt und - auch von den Naturwissenschaften! - nach wie vor unverstanden bleiben.

Dabei geht es um nichts weniger als das Verhältnis von Körper und Geist. In der philosophischen Tradition des deutschen Idealismus, dessen Bestreben es war, den Menschen vom Geist her zu verstehen, mögen viele Kulturalisten Gehirn und Geist noch immer als zwei unterscheidbare Entitäten ansehen. Wer jedoch bereit ist, ein wissenschaftliches Verstehen des Geistes in allen seinen Manifestationen (Erkennen, Empfinden, Erinnern, Denken usw.) als ein seriöses Vorhaben von Neurobiologie und Philosophie zu akzeptieren, wird davon ausgehen, dass Geist und Gehirn irgendwie physiologisch zusammenhängen. Aber wie genau man sich diesen Zusammenhang vorzustellen hat, ist trotz massiver Forschungsanstrengungen während der letzten Dekaden immer noch unklar.

Solange es keine belastbare evolutionäre Bewusstseinstheorie gibt, und eine solche erscheint angesichts neurobiologischer Wissenslücken und philosophischer Theorieschwächen noch nicht in Sicht, können Kulturalisten selbstbewusst auf einem dualistischen Weltbild bestehen. Weil Geist nicht Gehirn, also nicht bloße Natur sei, sondern etwas Besonderes, seien auch die Produkte des Geistes nicht 
bloße Natur. Mit dieser oft überzeugt geglaubten, aber faktisch doch nur vermuteten Feststellung nimmt jener Natur/Kultur-Antagonismus seinen Anfang, der dann folgerichtig in der Auffassung von der Unbestimmtheit der menschlichen Natur mündet. Sichtbarer Beleg dafür wäre eine besondere Erscheinungsform des Geistes, nämlich die (reine) Vernunft. Sie scheint die Grenzen des Machbaren weit hinaus schieben zu können. Mit reiner Vernunft in Alltag und Wissenschaft würde eine Tendenz zur Vervollkommnung der Welt etabliert, weil sie die Fußfesseln, die dem Menschen von der Natur angelegt worden sind, weitgehend zu sprengen vermag. Der Traum der Aufklärung wäre demnach keineswegs ausgeträumt.

Evos sind hinsichtlich der Möglichkeiten solcher Vernunft jedoch skeptisch, und zwar nicht nur, weil Alltag und Geschichte gleichermaßen lehren, wie wenig man ihr trauen kann. Den Grund für das wiederholte Scheitern an selbstgesteckten Vernunftzielen (Roth 2001) sehen Evos in dem Umstand, dass Gehirn und Geist eben doch eine biologisch evolvierte natürliche Einheit bilden und der Verstand eher als Kellner denn als Koch der persönlichen Interessen fungiert. Wer so monistisch denkt und seine philosophische Orientierung weniger im Idealismus, sondern eher in einem naturalistischen Materialismus sucht, für den sind auch die Leistungen des Gehirns klarerweise mit den Implikationen der natürlichen Selektion behaftet - und die Belege deuten durchaus deutlich in diese Richtung (siehe exemplarisch Cosmides und Tooby 2005).

\section{Was zu tun ist: Ein Ausblick}

Die hier versuchte Kartierung der Verständigungsbarrieren zwischen Evolutionisten und Kulturalisten mündet in der Feststellung, dass diese nur zum Teil wissenschaftlich seriös begründet sind. Trotz eines im Kern selben Forschungsgegenstands, den Wechselwirkungen von menschlichem Sozialverhalten und gesellschaftlichen Strukturen, haben beide Fraktionen im Laufe ihrer Disziplingeschichte für sich inhaltlich unterschiedliche Erklärungsinteressen paradigmenhaft etabliert und jeweils spezifisch wissenschaftstheoretisch grundiert. Allerdings hat sich auch gezeigt, dass diese Unterschiede nicht selten ,,aufgeblasen“ werden und viele paradigmatische Grenzziehungen weder gerechtfertigt noch dem wissenschaftlichen Ziel der Wahrheitsfindung dienlich sind. Und schon gar nicht verläuft die größte Verständigungsbarriere zwischen Natur- und Sozialwissenschaften, sondern zwischen Evolutionisten und Kulturalisten. Insgesamt ist die nach wie vor verbreitete Sprachlosigkeit zwischen Sozialwissenschaften und Evolutionsforschung demnach viel größer, als sie es eigentlich sein müsste.

Was also ist zu tun? Wünschenswert wäre eine konsequente Integration der beiden Forschungsgeschäfte, könnte sie doch nicht nur die gesellschaftliche Relevanz der Evolutionsforschung befördern, sondern auch eine handlungstheoretisch fundierte Konsolidierung der sozialwissenschaftlichen Theorievielfalt voranbringen (Schnettler 2016). Aber abgesehen von solchen eher langfristig angelegten Perspektiven lassen sich auch konkrete Forschungsfelder benennen, die in interdisziplinärer Kooperation erfolgversprechender zu bearbeiten wären als im fachlichen Alleingang. Schnittstellen dafür gibt es durchaus. Nur beispielhaft sei auf die Konvergenz von 
evolutionärer Lebensgeschichts- und sozialwissenschaftlicher Lebenslaufforschung (Bernardi et al. 2018; Stulp und Sear 2019) verwiesen, auf innovative Perspektiven zur Variabilität politischer Einstellungen (Aarøe et al. 2017) und Ideologien (Claessens et al. 2020) sowie auf das interdisziplinäre Schnittstellenpotenzial des Sozialkapitalkonzepts (Meißelbach 2019). Im Übrigen ist in jüngster Zeit die Herausbildung von Forschungsbereichen wie der Evolutionären Soziologie oder der Neurosoziologie zu beobachten. Dort und andernorts liegt viel Potenzial für einen weiteren Ausbau bestehender Ansätze evolutionärer Sozialwissenschaften (McDermott und Hatemi 2018; Van den Bergh 2018; Hopcroft 2016).

Großes Ziel sollte es letztlich sein, Durkheim und Darwin (wieder) in einen aufgeschlossenen und produktiven Dialog zu bringen. Dazu können Evolutionisten und Kulturalisten gleichermaßen beitragen. Durkheim ernst zu nehmen hieße, das theoretische Konstrukt der „Emergenz von sozialen Tatsachen“ so klar auszubuchstabieren, dass auch Evos ihren Nutzen für das Verständnis der Entstehung und Dynamik sozialer Makrophänomene erkennen. Dabei könnte die Komplexitätsforschung gute Dienste leisten. Darwin ernst zu nehmen bedeutet wiederum, auch solche sozialen Phänomene in modernen Gesellschaften evolutionstheoretisch abzubilden, mit deren Erklärung die Sozialwissenschaften bislang alleingelassen waren, weil sie von Evos sträflich vernachlässigt worden sind. Zu denken wäre hier etwa an Prozesse gesellschaftlichen Wertewandels oder Fragen politischer Legitimität. Im Erfolgsfall würde dies nicht nur beide Fraktionen stärken und zugleich gegenseitiges Verständnis sowie Wertschätzung vermehren. Es stiege auch die Chance, gemeinsam noch besser zur Lösung gesellschaftlicher Probleme beizutragen. Man könnte also einiges tun - und lohnen dürfte es sich allemal.

Funding Open Access funding enabled and organized by Projekt DEAL.

Open Access Dieser Artikel wird unter der Creative Commons Namensnennung 4.0 International Lizenz veröffentlicht, welche die Nutzung, Vervielfältigung, Bearbeitung, Verbreitung und Wiedergabe in jeglichem Medium und Format erlaubt, sofern Sie den/die ursprünglichen Autor(en) und die Quelle ordnungsgemäß nennen, einen Link zur Creative Commons Lizenz beifügen und angeben, ob Änderungen vorgenommen wurden.

Die in diesem Artikel enthaltenen Bilder und sonstiges Drittmaterial unterliegen ebenfalls der genannten Creative Commons Lizenz, sofern sich aus der Abbildungslegende nichts anderes ergibt. Sofern das betreffende Material nicht unter der genannten Creative Commons Lizenz steht und die betreffende Handlung nicht nach gesetzlichen Vorschriften erlaubt ist, ist für die oben aufgeführten Weiterverwendungen des Materials die Einwilligung des jeweiligen Rechteinhabers einzuholen.

Weitere Details zur Lizenz entnehmen Sie bitte der Lizenzinformation auf http://creativecommons.org/ licenses/by/4.0/deed.de.

\section{Literatur}

Aarøe, Lene, Michael Bang Petersen und Kevin Arceneaux. 2017. The Behavioral Immune System Shapes Political Intuitions: Why and How Individual Differences in Disgust Sensitivity Underlie Opposition to Immigration. American Political Science Review 111:277-294.

Albert, Gert, Jens Greve und Rainer Schützeichel (Hrsg.). 2016. Kooperation, Sozialität und Kultur. Michael Tomasellos Arbeiten in der soziologischen Diskussion. Zeitschrift für Theoretische Soziologie, 3. Sonderband. Weinheim: Beltz Juventa. 
Baldus, Bernd. 2002. Darwin und die Soziologie: Kontingenz, Aktion und Struktur im menschlichen Sozialverhalten. Zeitschrift für Soziologie 31:316-331.

Bateson, Patrick, und Kevin N. Laland. 2013. Tinbergen's four questions: An appreciation and an update. Trends in Ecology and Evolution 28:712-718.

Bauman, Zygmunt. 1995. Postmoderne Ethik. Hamburg: Hamburger Edition.

Van den Bergh, Jeroen C. J. M. 2018. Human Evolution beyond Biology and Culture. Evolutionary Social, Environmental and Policy Sciences. Cambridge, New York: Cambridge University Press.

Bernardi, Laura, Johannes Huinink und Richard A. Settersen Jr. 2018. The life course cube. A tool for studying lives. Advances in Life Course Research. doi: 10.1016/j.alcr.2018.11.004.

Bianchin, Matteo. 2015. From joint attention to communicative action. Some remarks on critical theory, social ontology and cognitive science. Philosophy \& Social Criticism 41:593-608.

Bourdieu, Pierre. 1985. Sozialer Raum und „Klassen“: Zwei Vorlesungen. Frankfurt/M.: Suhrkamp.

Brown, Chris. 2013. "Human nature", science and international political theory. Journal of International Relations and Development 16:435-454.

Buss, David M., und William von Hippel. 2018. Psychological barriers to evolutionary psychology: Ideological bias and coalitional adaptations. Archives of Scientific Psychology 6:148-158.

Carroll, Joseph, John A. Johnson, Catherine Salmon, Jens Kjeldgaard-Christianssen, Mathias Clasen und Emelie Jonsson. 2017. A cross-disciplinary survey of beliefs about human nature, culture, and science. Evolutionary Studies in Imaginative Culture 1:1-32.

Claessens, Scott, Kyle Fischer, Ananish Chaudhuri, Chris G. Sibley und Quentin D. Atkinson. 2020. The dual evolutionary foundations of political ideology. Nature Human Behaviour 4:336-345.

Comtesse, Dagmar, Oliver Flügel-Martinsen, Franziska Martinsen und Martin Nonhoff. 2019. Einleitung. In Radikale Demokratietheorie. Ein Handbuch, Hrsg. Dagmar Comtesse, Oliver Flügel-Martinsen und Franziska Martinsen, 11-27, Berlin: Suhrkamp.

Cosmides, Leda, und John Tooby. 2005. Neurocognitive adaptations designed for social exchange. In The Handbook of Evolutionary Psychology, Hrsg. David M. Buss, 584-627. Hoboken: Wiley.

Cosmides, Leda, und John Tooby. 1997. Evolutionary Psychology-A Primer. https://www.cep.ucsb.edu/ primer.html (Zugegriffen: 8. Juli 2020).

Crippen, Timothy. 2018. Evolutionary behavioral science-Core principles, common misconceptions, and a troubling tendency. In The Oxford Handbook of Evolution, Biology, and Society, Hrsg. Rosemary L. Hopcroft, 423-450. Oxford: Oxford University Press.

Dobzhansky, Theodosius. 1973. Nothing in biology makes sense except in the light of evolution. The American Biology Teacher 35:125-129.

Durkheim, Émile. 1961 [ursprüngl. 1895]. Die Regeln der soziologischen Methode - Les règles de la méthode sociologique. Übersetzt von René König. Neuwied: Luchterhand.

Eibl, Karl. 2009. Kultur als Zwischenwelt: Eine evolutionsbiologische Perspektive. Frankfurt/M.: Suhrkamp.

Esser, Hartmut. 2018. Engführung? Ergänzungen zu einem unerledigten Fall. Zeitschrift für Theoretische Soziologie 7:251-273.

Foucault, Michel. 1971. Die Ordnung der Dinge. Eine Archäologie der Humanwissenschaften. Frankfurt/M.: Suhrkamp.

Foucault, Michel. 1974. Von der Subversion des Wissens. München: Hanser.

Geertz, Clifford. 1973. The Interpretation of Cultures. Selected Essays. New York: Basic Books.

Geher, Glenn, und Daniel Gambacorta. 2010. Evolution is not relevant to sex differences in humans because I want it that way! Evidence for the politicization of human evolutionary psychology. Journal of the Evolutionary Studies Consortium 2:32-47.

Greve, Jens, und Annette Schnabel (Hrsg.). 2011. Emergenz: Zur Analyse und Erklärung komplexer Strukturen. Berlin: Suhrkamp.

Henrich, Joseph, und Richard McElreath. 2003. The Evolution of Cultural Evolution. Evolutionary Anthropology: Issues, News, and Reviews 12:123-135.

Henrich, Joseph, Steven J. Heine und Ara Norenzayan. 2010. The weirdest people in the world? Behavioral and Brain Sciences 33:61-83.

Hirschauer, Stefan. 2018. Der Quexit. Das Mannemer Milieu im Abseits der Soziologie. Zeitschrift für Theoretische Soziologie 7:153-167.

Hopcroft, Rosemary L. 2016. Grand Challenges in Evolutionary Sociology and Biosociology. Frontiers in Sociology 1. doi:10.3389/fsoc.2016.00002.

Horowitz, Mark, William Yaworsky und Kenneth Kickham. 2014. Wither the Blank Slate? A report on the reception of evolutionary biological ideas among sociological theorists. Sociological Spectrum 34:489-509. 
Jonason, Peter K., und David P. Schmitt. 2016. Quantifying common criticisms of evolutionary psychology. Evolutionary Psychological Science 2:177-188.

Laland, Kevin N., und Gillian R. Brown. 2002. Sense and Nonsense. Evolutionary Perspectives on Human Behaviour. Oxford, New York: Oxford University Press.

Laland, Kevin N., Tobias Uller, Marcus W. Feldman, Kim Sterelny, Gerd B. Müller, Armin Moczek, Eva Jablonka und John Odling-Smee. 2015. The extended evolutionary synthesis: Its structure, assumptions and predictions. Proceedings of the Royal Society B 282:20151019.

Leahy, Terry. 2012. The elephant in the room: Human nature and the sociology textbooks: Current Socio$\log y$ 60:806-823.

Lieberman, Leonard. 1989. A discipline divided: Acceptance of human sociobiological concepts in anthropology. Current Anthropology 30:676-682.

Lopreato, Joseph, und Timothy Crippen. 1999. Crisis in sociology: The need for Darwin. New Brunswick, NJ: Transaction.

Lorenz, Konrad. 1963. Das sogenannte Böse. Wien: Borotha-Schoeler.

Lowie, Robert H. 1966 [ursprüngl. 1917]. Culture and Ethnology. New York: Basic Books.

Lyle III, Henry F., und Eric A. Smith. 2012. How conservative are evolutionary anthropologists? A survey of political attitudes. Human Nature 23:306-322.

Lyotard, Jean-François. 1986. Das postmoderne Wissen: Ein Bericht. Wien: Böhlau.

Marquard, Odo. 1974. Inkompetenzkompensationskompetenz. Philosophisches Jahrbuch 81:341-349.

Mayr, Ernst. 1988. Die Darwinsche Revolution und die Widerstände gegen die Selektionstheorie. In Die Herausforderung der Evolutionsbiologie. Hrsg. Heinrich Meier, 221-250. München und Zürich.

McDermott, Rose, und Peter K. Hatemi. 2018. To go forward, we must look back: The importance of evolutionary psychology for understanding modern politics. Evolutionary Psychology 16:1-7.

Meißelbach, Christoph. 2018. Wider die Antagonismen. In Politikwissenschaft als Beruf: Perspektiven aus Wissenschaft und Gesellschaft, Hrsg. Christoph Meißelbach, Jakob Lempp und Stephan Dreischer, 213-242. Wiesbaden: Springer VS.

Meißelbach, Christoph. 2019. Die Evolution der Kohäsion. Sozialkapital und die Natur des Menschen. Wiesbaden: Springer VS.

Mesoudi, Alex. 2011. Cultural Evolution: How Darwinian Theory Can Explain Human Culture and Synthesize the Social Sciences. Chicago: University of Chicago Press.

Mesoudi, Alex. 2017. Pursuing Darwin's curious parallel: Prospects for a science of cultural evolution. Proceedings of the National Academy of Sciences 114:7853-1860.

Mesoudi, Alex, Djuke Veldhuis und Robert A. Foley. 2010. Why aren't the social sciences darwinian? Journal of Evolutionary Psychology 8:93-104.

Odling-Smee, F. John, Kevin N. Laland und Marcus W. Feldman. 2003. Niche Construction: The Neglected Process in Evolution. Princeton, NJ: Princeton University Press.

Opp, Karl-Dieter. 2014. Das Aggregationsproblem bei Mikro-Makro-Erklärungen. Kölner Zeitschrift für Soziologie und Sozialpsychologie 66:155-188.

Penke, Lars, Jaap J. A. Denissen und Geoffrey F. Miller. 2007. The evolutionary genetics of personality. European Journal of Personality 21:549-587.

Perry, George, und Ruth Mace. 2010. The lack of acceptance of evolutionary approaches to human behavior. Journal of Evolutionary Psychology 8:105-125.

Pinker, Steven. 2003. Das unbeschriebene Blatt. Berlin: Berlin.

Richerson, Peter J., und Robert Boyd. 2005. Not by Genes alone. How Culture Transformed Human Evolution. Chicago: University of Chicago Press.

Richter, Dirk. 2005. Das Scheitern der Biologisierung der Soziologie. Kölner Zeitschrift für Soziologie und Sozialpsychologie 57:523-542.

Rorty, Richard. 1988. Solidarität oder Objektivität? drei philosophische Essays. Stuttgart: Reclam.

Roth, Gerhard. 2001. Fühlen, Denken, Handeln. Wie das Gehirn unser Verhalten steuert. Frankfurt/M.: Suhrkamp.

Runciman, W. G. 2008. Forgetting the founders. Sociological Review 56:358-369.

Ruse, Michael. 1995. Evolutionary Naturalism. Selected Essays. London, New York: Routledge.

Scheunpflug, Annette. 2015. Die Natur der Sozialisation - zur Anthropologie eines erziehungswissenschaftlichen Begriffs. Zeitschrift für Erziehungswissenschaft 18:69-88.

Schnettler, Sebastian. 2016. Evolutionäre Soziologie. Soziologische Revue 39:507-536.

Segerstråle, Ulica. 2000. Defenders of the Truth. The Battle for Science in the Sociobiology Debate and Beyond. Oxford: Oxford University Press.

Slingerland, Edward. 2008. Good and Bad Reductionism: Acknowledging the Power of Culture. Style 42:266-271. 
Stulp, Gert, und Rebecca Sear. 2019. How might life history theory contribute to life course theory? Advances in Life Course Research. DOI: 10.1016/j.alcr.2019.04.011.

Tinbergen, Nicolaas. 1963. On aims and methods of ethology. Zeitschrift für Tierpsychologie 20:410-433.

Tomasello, Michael. 2014. Eine Naturgeschichte des menschlichen Denkens. Berlin: Suhrkamp.

Tooby, John, und Leda Cosmides. 1992. The psychological foundations of culture. In The Adapted Mind-Evolutionary Psychology and the Generation of Culture. Hrsg. Jerome H. Barkow, Leda Cosmides und John Tooby, 19-136. New York, Oxford: Oxford University Press.

Turner, Jonathan H., und Alexandra Maryanski. 2015. The prospects and limitations of evolutionary theorizing in the social sciences. In Handbook on Evolution and Society: Toward an Evolutionary Social Science, Hrsg. Jonathan H. Turner, Richard Machalek und Alexandra Maryanski, 92-111. Boulder, CO: Paradigm.

Tybur, Joshua M., Geoffrey F. Mille und Steven W. Gangested 2007. Testing the controversy. An empirical examination of adaptationists' attitudes toward politics and science. Human Nature 18:313-328.

Vogel, Christian. 1988. Gibt es eine natürliche Moral? Oder: Wie widernatürlich ist unsere Ethik? Civis Vierteljahresschrift für freie Bürger in einem freiheitlichen Staat. 1/88:65-78.

Voland, Eckart. 2006. Lernen - Die Grundlegung der Pädagogik in evolutionärer Charakterisierung. Zeitschrift für Erziehungswissenschaft Beiheft 5/2006:103-115.

Weingart, Peter, Sandra D. Mitchell, Peter J. Richerson und Sabine Maasen. (Hrsg.). 1997. Human by Nature. Between Biology and the Social Sciences. Mahwah, London: Erlbaum.

Welsch, Wolfgang. 1994. Einleitung. In Wege aus der Moderne: Schlüsseltexte der Postmoderne-Diskussion, Hrsg. Wolfgang Welsch, 1-43. Berlin: Akademie Verlag.

Whitehead, Hal, Kevin N. Laland, Luke Rendell, Rose Thorogood und Andrew Whiten. 2019. The reach of gene-culture coevolution in animals. Nature Communications 10:2405. doi: 10.1038/s41467-01910293-y.

Winegard, Benjamin M., Bo M. Winegard und Robert O. Deaner. 2014. Misrepresentations of evolutionary psychology in sex and gender textbooks. Evolutionary Psychology 12:474-508.

Eckart Voland 1949, Prof. Dr., Professor im Ruhestand, Institut für Philosophie der Universität GieBen. Forschungsgebiete: Philosophie der Biowissenschaften, Evolutionäre Anthropologie, Historische Demografie. Veröffentlichungen: Evolution des Gewissens - Strategien zwischen Eigennutz und Gehorsam. Stuttgart 2014 (mit R. Voland); Soziobiologie - Evolution von Kooperation und Konkurrenz, Heidelberg 2013; mehr unter: www.eckart-voland.de.

Christoph Meißelbach 1979, Dr. phil., Wissenschaftlicher Mitarbeiter, Sächsisches Institut für Polizeiund Sicherheitsforschung an der Hochschule der Sächsischen Polizei (FH). Forschungsgebiete: Evolutionäre Politische Soziologie, Digitale Demokratie, Sicherheitsforschung. Veröffentlichungen: Die Evolution der Kohäsion - Sozialkapital und die Natur des Menschen. Springer 2019; Wider die Antagonismen - Methodologische Grundlagen der Politikwissenschaft. In: Politikwissenschaft als Beruf, Hrsg. C. Meißelbach et al., Springer 2018. 